\title{
SOBRE CRIATIVIDADE, TEMPO E PENSAMENTO EM DIFERENTES ÁREAS DAS INDÚSTRIAS CRIATIVAS
}

\section{ON CREATIVITY, TIME, AND THOUGHT IN DIFFERENT AREAS OF THE CREATIVE INDUSTRIES}

\author{
Patrícia Cecília BURROWES ${ }^{1}$
}

\section{Resumo:}

Este trabalho decorre da pesquisa Criatividade e Indústrias Criativas, em que é problematizada a noção de criatividade. Nessa área da economia se arrolam atividades diversas cujo traço em comum seria lançarem mão da criatividade como um recurso econômico essencial na formação do preço. Detenho-me aqui em duas áreas: arte e publicidade. Este artigo aborda suas aproximações e distanciamentos, a partir de observação participante em ateliês, conversas com artistas, uma visita à exposição $O$ Consumo Feliz, e a experiência como redatora publicitária. $\mathrm{O}$ conceito de contemporâneo em Agamben, a noção de campo criador de Caiafa e estudos sobre processos criativos, de Ostrower, são base para a discussão dos agenciamentos coletivos de enunciação (Deleuze \& Guattari) em questão e das subjetividades aí produzidas.

Palavras-chave: Criatividade; processos criativos; indústrias criativas; subjetividade.

\begin{abstract}
:
This paper stems from the research Creativity and Creative Industries in which the notion of creativity is problematized. In this area of economy several activities are listed who share the common trait of using creativity as an essential economic resource for the formation of price. In this paper I examine two sectors: art and advertising. Based on participant observation in art studios, conversations with artists, a visit to the exposition Happy Consumption, and my past experience as advertising copywriter, I analyse the ways art and advertising come close to each other and the ways they differ. Agamben's concept of contemporary, Caiafa's notion of creative field, and Ostrower's studies on creative processes, along with Deleuze \& Guattari afford the theory for the discussion of collective assemblage of enunciation in question and the subjectivities thus produced.
\end{abstract}

Keywords: Creativity; creative processes; creative industries; subjectivity.

$1 \quad$ Profa. Adjunta do Departamento de Expressão e Linguagens (DEL), Escola de Comunicação Universidade Federal do Rio de Janeiro (ECO/UFRJ).E-mail: vermelha.red@gmail.com. 
Introdução

Desde o final da década de 1990, termos como Economia Criativa, Indústria Criativa, Setores Criativos começaram a circular, primeiro nos discursos de governos e organizações internacionais, depois na mídia internacional, ganhando crescentes visibilidade e centralidade, e chegando mais tarde à mídia brasileira. Tal vocabulário vinha carregado de otimismo, associado a promessas de desenvolvimento sustentável, produção de riqueza, distribuição de renda, uma verdadeira panaceia contra a crise econômica, especialmente depois de 2008.

Não é difícil retomar o fio da meada da história que nos leva a meados da década de 1990. Uma breve cronologia incluiria alguns momentos-chaves:

- 1994- na Austrália o primeiro ministro apresentava a primeira política cultural formal do país e a definia como uma política econômica -documento intitulado Creative Nation;

- $\quad$ 1997- Tony Blair, chega ao poder e ergue a bandeira Creative Britain numa tentativa de reposicionar o Reino Unido no mercado globalizado;

- 2004 (outubro)- é criada a Creative Cities Network - Rede mundial de cidades criativas no âmbito da UNESCO;

- 2006- o conceito de Indústrias Criativas é incorporado pela União Europeia;

- 2008- UNCTAD - United Nations Conference on Trade and Development : publica o primeiro relatório sobre a Economia Criativa;

- 2011- no Brasil: o Ministério da Cultura (MINC) estrutura a Secretaria da Economia Criativa, (MINC, 2011)

- 2013- ocorre o primeiro Encontro Global da Classe Criativa, um sub-evento do Forum Mundial da Comunicação, em Davos.

A partir de então, Economia Criativa e Indústria Criativa se tornaram expressões cada vez mais presentes no cotidiano, sendo frequentemente evocadas para justificar políticas públicas, empregadas para valorizar empreendimentos privados e largamente usadas sem grande explicação sobre aquilo a que se referem. Nesse contexto, inquietou-me o fato de ficarem à sombra das promessas de desenvolvimento e prosperidade questões como a contradição existente entre os termos "indústria" e 
"criativa"; a possibilidade de se ter uma produção em escala industrial de materiais criativos; o fato de a criatividade ser vista como mais um recurso a ser explorado (por quem?) na produção de riqueza. Assim, iniciei pesquisa, com intuito de investigar em que sentido se emprega a palavra "criatividade" e a que se referia a noção de "criativo" na crescente Indústria Criativa.

Diante da grande variedade e diversidade de atividades consideradas parte desse setor da economia - arquitetura, artesanato, cinema, design, mercado de artes e antiguidades, mercado editorial, moda, música, artes cênicas, publicidade, software e games, rádio e televisão - e da dificuldade de acompanhar todos eles, foi necessário fazer um recorte. Este se baseou na conveniência, conforme a experiência e proximidade da pesquisadora: publicidade e artes visuais. São elas, segundo a classificação da United Nations Conference on Trade and Development (Conferência das Nações Unidas sobre Comércio e Desenvolvimento), uma atividade downstream (mais próxima do mercado, tais como publicidade, edição e atividades relacionadas com a mídia) e outra, upstream (atividades culturais tradicionais como artes cênicas e visuais). Ademais, publicidade e arte compartilham da definição de base proposta pela Conferência: sua produção emprega a criatividade como recurso; os bens produzidos incorporam mensagens simbólicas para quem os consome; contém, ainda que potencialmente, propriedade intelectual atribuível à pessoa ou ao grupo que o produz (UNCTAD, 2008, p.10). Alinham-se também sob o conceito elaborado pela Secretaria da Economia Criativa, ligada ao Ministério da Cultura do Brasil: são atividades produtivas que têm como processo principal "um ato criativo gerador de valor simbólico, elemento central da formação de preço, e que resulta em produção de riqueza cultural e econômica."(MINC, 2011)

A metodologia fundou-se no método cartográfico, com observação participante. Entre 2013 e 2017 acompanhei ateliers de arte para conviver mais proximamente com artistas e conhecer o dia a dia da produção. Nesse período, por três anos frequentei o atelier livre de gravura do SESC Tijuca e o atelier de pintura da artista Katie von Scherpenberg. Os encontros eram semanais e voltados para a produção individual. Isso me permitiu conviver e conversar com artistas de diferentes idades, diferentes 
backgrounds e em diferentes momentos de sua carreira. No atelier de gravura o número de frequentadores chegava a doze, mas eram quatro os mais próximos e assíduos; no de pintura, três. Não trabalhei com o formato de entrevistas estruturadas ou semiestruturadas, mas com a conversação espontânea dos ateliers. Além disso, me dediquei a visitar exposições e colher os materiais de apresentação nelas disponíveis folhetos, catálogos - e, posteriormente, analisei seus textos. Foram estudadas vinte dessas peças, colhidas em espaços institucionais não comerciais de exposição: Centro Cultural Banco do Brasil, Caixa Cultural, Casa Daros, Escola de Artes Visuais, Museu Nacional de Belas Artes, Paço Imperial, MAM, MASP, Galeria Cândido Portinari (UERJ), galeria SESC. Como a experiência de produção na publicidade, no departamento de criação, é-me conhecida devido a um longo período de prática profissional, direcionei minha atenção para as peças produzidas em momentos chaves da história da publicidade.

\section{Uma exposição de "Arte Publicitária"}

No mês de abril de 2014, realizava-se no Museu Berardo, em Lisboa, uma exposição temporária intitulada "O Consumo Feliz. Publicidade e sociedade no século XX." Ali eram mostrados originais de peças publicitárias produzidas na empresa inglesa James Haworth \& Company, cujo período de atuação cobriu a maior parte do século XX, desde os anos 1900 até a década de 1980.

A intensa produção da firma, com milhares de trabalhos de vastíssima expansão, espelho e motor do consumo, permite não só um olhar detalhado sobre o fenômeno da publicidade e do marketing como, ainda, pelo seu interesse estético inigualável, uma panorâmica original para a compreensão do design gráfico e das próprias artes visuais contemporâneas. (SANTOS, 2014, $\mathrm{s} / \mathrm{p})$

Disponível na loja do museu, o catálogo da exposição trazia um título provocador: "Catálogo da Coleção Berardo de Arte Publicitária". Na ampla galeria que acolhia os mais de 350 originais de reclames publicitários alinhavam-se, um após o outro, desenhos, aquarelas, guaches feitos à mão, em que se evidenciam o bom uso da técnica; são notáveis a atenção para a composição, a escolha de cores, a perspectiva, a luz e os contrastes, a coerência do estilo. É fácil reconhecer influências do Neoplasticismo no estilo Déco de um cartaz para Orient Line, de 1925; uma alusão ao 
Construtivismo em um anúncio para a semana de armas de guerra, de 1941; e uma ligação com as composições geométricas Modernistas numa peça para Sunbeam/Rootes, de 1965. Temos ainda um anúncio de companhia aérea, de 1955, que flerta com o Surrealismo de Magritte. Referências, alusões, flertes que remetem a diferentes momentos da arte moderna, guardando, no entanto, deles uma distância perceptível.

Esses momentos estão também presentes no museu, por meio de obras de diversos artistas, reunidas nos dois andares de exposição permanente dedicados à arte do século XX: o segundo pavimento abriga obras de arte produzidas entre 1900 e 1960; no primeiro andar, estão trabalhos da década de 1960 até 2010. Ali encontramos um percurso que vai do Cubismo à Pop Art americana, num passeio inquietante pelas vanguardas artísticas europeias e suas sucessoras. A Tête de Femme (1909), de Picasso, lembra-nos como o Cubismo desafia nossa compreensão da representação do espaço e dos volumes; o Porta-garrafas (1914) de Duchamps problematiza ainda hoje as noções de arte e artista; o desenho Suprematism: 34 drawings (1920), de Malevich, a litografia Konstruction (Kestnermappe 6) 1922, de Moholy-Nagy, o óleo Tableau (amarelo, preto, azul, vermelho e cinzento), 1923, de Mondrian colocam-nos diante das possibilidades abertas pela abstração geométrica para dar a ver o sentimento, a sensação, a percepção; de Miró, Figure à la Bougie (1925), abre-nos os olhos para a poesia existente em uma mera parede manchada; Le Gouffre Argenté (1926), de Magritte, reúne elementos díspares e nos oferece o abismo de um enigma sem resposta evidente, como num sonho. Poderíamos avançar na descrição quase que ano a ano e teríamos obras-experimentos que impulsionaram as linguagens do desenho, da pintura, da gravura, da fotografia, do vídeo, ou mesmo inauguram novas linguagens, ou exploraram e indagaram até os seus limites os caminhos abertos por outras. Mas os poucos títulos mencionados são já o suficiente para nos ajudar a pensar sobre nossa questão: seria a publicidade arte?

Antes de prosseguir, no entanto, é fundamental fazer uma ressalva. Tentar definir de maneira universal o que é e o que não é arte, não só ultrapassa a proposta e o escopo deste artigo, como seria seguir uma pista falsa, entrar num beco sem saída. Umberto Eco (2011 [1981]), para mencionar apenas um, já se deteve nesse problema. Embora necessária, a definição da arte é mutável e fugidia. Toda tentativa de conceituar 
filosoficamente a artisticidade será inevitavelmente localizada no tempo e no espaço, ou seja, sujeita à historicidade, bem como está sujeito à historicidade esse pensamento sobre a arte. Finalmente talvez chegaríamos à formulação de Frederico Morais "Arte é o que eu e você chamamos arte" (MORAIS, 2002). O que propomos fazer é, a partir dos casos em estudo, considerar as potências ativadas, as conexões que se estabelecem, os discursos evocados, o modo como se espera que pessoas sejam afetadas em cada uma das áreas de produção em análise.

\section{Tempo de consumir, tempo para pensar}

Salta aos olhos, logo na primeira observação dos trabalhos de uma e outra mostras, ou seja, da exposição de originais da publicidade e de obras de arte do início do século XX, a defasagem de datas. É inegável que a arte é primeira na investigação e na proposição de modos de pensar e ver, representar e não representar, interrogar e interferir no mundo; a publicidade vem depois, no rastro, recolhendo e reaproveitando elementos novos e conjugando-os com antigos. Mas não deve estar aí a principal diferença, afinal, também a arte retoma elementos de outras épocas, culturas e âmbitos, recombinando-os, transformando-os, dando-lhes outros sentidos.

Não se trata puramente de datação, de uma anterioridade ou posterioridade no emprego de técnicas, mas de uma relação com o tempo. Poderíamos dizer que as obras de arte mencionadas acima, embora classificadas como modernas na história da arte, permanecem contemporâneas, no sentido que Agamben (2009) traz para esse termo.

Ser contemporâneo significa, em Agamben, guardar uma diferença com relação à própria época. Refere-se ao intempestivo nietzscheano, ou seja algo não só inesperado, mas que chega em hora imprópria, inoportuno. Algo que não se adequa às pretensões do tempo sendo, portanto, inatual. Mas tal anacronismo, prossegue o autor, esse descolamento do tempo corrente é o que lhe dá a situação necessária para apreender aquilo de que se distancia. Contemporâneo seria assim "uma singular relação com o próprio tempo, que adere a este e, ao mesmo tempo, dele toma distâncias". (AGAMBEN, 2009, p.59) 
A contemporaneidade da obra de arte se mantém viva através do tempo, ela guarda sempre essa diferença, um grão de estranheza que reverbera a cada olhar. A surpresa, ou incômodo, ou mesmo rejeição que se elevaram quando de sua primeira exposição não se esgotaram no passado, ao contrário, permanecem presentes, interpelando o olhador, desafiando-o de alguma forma a sair do reconfortante conhecido, a estranhar e portanto estranhar-se. E a obra não oferece respostas, não indica uma maneira que seria a certa de agir ou pensar diante desse desconforto.

Aquilo que em sua inquestionável atualidade adere completamente ao seu tempo não o pode enxergar, por isso, não pode ser contemporâneo. É o caso da publicidade: por necessidade intrínseca ela pertence ao seu tempo, está na plena luz da sua época. $\mathrm{O}$ interesse despertado pela publicidade antiga deve-se justamente a essa sua adesão; nela vemos o que já não é; o tempo passado assinala um afastamento do presente, mas é um outro tipo de afastamento, uma nostalgia; não é um estranhamento, mas um reconhecimento, sabemos que 'naquele tempo era assim'. Mesmo se considerarmos casos que levantam polêmica devido a um mal-estar junto a certos grupos sociais, como um recente comercial de perfumes que suavemente aludia a amores homossexuais, o que transparece é um fato totalmente imerso no e adequado ao seu tempo presente, a questão já estava colocada antes de ser abordada num anúncio. A peça publicitária simplesmente encena uma resposta coerente com seu tempo, instrui quanto ao comportamento a ser adotado diante da questão, remete-a ao repertório de situações e atitudes conhecidas de modo que quase a isenta de arestas. Acolhe alegremente uma diferença, que se resolve pela incorporação, enquanto deixa fora do questionamento inúmeras outras.

Ainda nessa relação que estabelece com o tempo, mas agora, com tempo de fruição, reside uma potência específica da arte. É o pensamento que Caiafa desenvolve em Nosso século XXI (CAIAFA, 2000). A pergunta aqui é: qual é o tempo da arte e do pensamento? "Tempo de ressonâncias" (idem, p.25), propõe a autora. Diferentemente de produções ditadas pelo mercado, que almejam uma eficácia, pois demandam um retorno calculado para o investimento, arte e pensamento têm uma duração da ordem do imprevisível e com uma dimensão inesgotável. São imagens, cores, gestos, sons, frases 
que, acolhidas na subjetividade, não se esgotam de uma vez, conservam sempre uma força de germinação, e voltam renovadas a cada encontro: "como uma dádiva" (idem, p.21). Saímos do âmbito e da velocidade do consumo - ainda que livros, filmes, telas sejam comprados e vendidos como mercadorias, seu vigor não se encerra na circulação. Caiafa correlaciona a duração com o modo de incidência no desejo: se o consumo instantaneamente satisfaz o impulso que o motivou, abrindo espaço para a repetição do gesto, a arte não estanca o desejo que se conecta a ela, o realimenta, assim pode "repercutir mais além e em seguida, muito depois, num lapso que é do domínio mesmo da criação.” (idem, p.24)

A ideia proposta pela autora de um processo criativo evocado pela arte, que não diz respeito somente à sua gênese, mas se lança para o futuro, envolvendo o leitor no "campo criador" da obra, se distingue das exigências de interatividade e participação do público cada vez mais presentes na publicidade. Não se trata, no caso da arte, de apenas produzir uma resposta que preencha uma lacuna, nem de induzir a um gesto, clique, comentário capaz de replicar a mensagem fazendo-a atingir um número cada vez maior de pessoas. Trata-se de convidar a criar. "Sou contagiado pelo processo de criação quando sou chamado a criar a partir da obra e não a dispor dela como de uma informação." (idem, p.35)

\section{Criatividade ou invenção?}

A potência contagiante de criação inerente à arte é também coisa distinta da "criatividade" valorizada e perseguida pelo menos desde a revolução criativa da década de 1960 no ambiente da comunicação de marcas, notadamente na publicidade. Como desenvolvi em artigo anterior (BURROWES, 2014), a criatividade começou a ser empregada nas peças publicitárias como forma de tornar mais atraentes e convincentes, por meio do tratamento estético e da associação com benefícios imateriais, as ofertas e promessas das empresas quanto aos seus produtos e serviços. Essa criatividade é algo facilmente reconhecível pela pequena surpresa que produz, seguida de uma satisfação por se conseguir, sem grande dificuldade, refazer o percurso do deslocamento, desvendar o truque, ou seja, entender a mensagem. E ser compreendida pelo público é aqui condição para a eficácia da comunicação. A centralidade dessa noção de 
criatividade no setor da publicidade é expressa, por exemplo, pelo título do mais prestigioso concurso da área, o Festival Internacional de Criatividade de Cannes. Aplicada à solução de problemas de mercado, a criatividade é vista como uma panaceia; aquilo que garantirá o sucesso da comunicação, dos profissionais, da marca, que conquistará o coração e a mente do público e, espera-se, resultará em muitas vendas e no crescimento do valor da empresa.

A própria noção de criatividade é problematizada por Kastrup (2007), em seus estudos sobre o fenômeno da invenção. A autora diferencia os dois termos, criatividade e invenção, no âmbito da psicologia da cognição. Nesse campo, os estudos sobre a criatividade surgiram na década de 1950 nos Estados Unidos, num momento de grande expansão do capitalismo e da indústria, quando a produção em franco crescimento necessitava de profissionais que atendessem a demanda insaciável por novidades da florescente sociedade de consumo. A criatividade foi então definida como a capacidade de propor soluções para problemas dados, seria uma das capacidades da inteligência e, como tal, passível de ser medida, desenvolvida e treinada. A crítica de Kastrup incide no fato da função criativa ser aí submetida a uma finalidade objetiva, pontual, de alcance limitado e limitador. A autora afirma que a questão da criação fica mal colocada quando lida pelo viés da criatividade. Sugere ainda ser a função de criação uma tendência de natureza diferente da tendência intelectual; ou seja que ela diverge em relação à inteligência. Para a autora há uma contradição na tentativa de estabelecer um funcionamento geral (uma lei, uma estrutura, um modelo) para a criação, uma vez que ela se caracteriza por trazer à vista o inesperado, o que antes não poderia ter sido vislumbrado.

Se na psicologia da cognição, segundo Kastrup, a questão da invenção nunca foi bem colocada, na arte os escritos e reflexões de artistas como Ostrower (2004) a propósito dos processos criativos a abordam em sua complexidade e abrangência. Ainda que com frequência se utilize do próprio termo "criatividade", o que pode produzir certa confusão, essa é vista como potencial humano fundamental, constitutivo mesmo dos processos de apreensão, compreensão e transformação do ser no mundo, e não redutível à inteligência, uma vez que inclui aspectos sensíveis, intuitivos, afetivos, inconscientes 
e culturais. Ou seja, a criatividade não é posta como uma capacitação ligada à arte ou a determinadas profissões artísticas, mas como faculdade compartilhada e presente cotidianamente em todas as esferas da vida, melhor expressa pelo termo "potencial criador" (OSTROWER, 2004, p.26).

A artista, que de 1978 a 1982, presidiu à comissão brasileira da International Society of Education through Art, INSEA, da UNESCO, descreve o funcionamento geral dessa faculdade humana, apontando mesmo para a constante formação de estruturas contextuais sem, no entanto, propor um modelo fechado, com validade universal. A abertura do processo é garantida pela compreensão do potencial criador como uma busca de sentido, com base em uma experiência de viver necessariamente singular. A busca é sempre renovada, uma vez que as configurações são parciais, momentâneas e alimentam, elas próprias, inúmeras possibilidades até então imprevisíveis. Já o processo criativo, segundo a visão de Ostrower, é uma experiência associada a um trabalho, um fazer concreto no qual o potencial criador se realiza; nele, no caso da arte, se elabora uma questão colocada pelo próprio "formador" (idem, p.9) em interpelação ao seu tempo e lugar, em relação com sua época, mas sem colar-se a ela, como destacou Agamben, acima mencionado.

\section{Pensamento e experimentação}

$\mathrm{Na}$ arte, a criatividade parece não ser a questão. De um trabalho, no âmbito da arte, raramente se diz ser criativo. Os atributos são outros. Diz-se: consistente, pertinente, que faz pensar, que faz perguntas sem tentar responder, dramático, perturbador, belo, estranho, inquietante, incompreensível, até mesmo original. Essas são expressões encontradas nos vinte catálogos e folhetos de exposições analisados no decorrer desta pesquisa. Nesses vinte materiais aleatoriamente colhidos em espaços institucionais como galerias e centros culturais, nenhum texto crítico emprega o adjetivo criativo, ou o substantivo criatividade na apresentação do artista ou na descrição de sua obra. Além disso, em três anos de observação participante frequentando um atelier de gravura e um atelier de pintura, bem como, anteriormente, um curso na Escola de Artes Visuais do Parque Lage, verifiquei ser a noção de criatividade desimportante para professores e frequentadores. A palavra sequer surgia espontaneamente nas conversas. 
Em uma ocasião, quando perguntei diretamente à artista e professora de pintura, Katie van Scherpenberg, acerca de sua visão sobre a criatividade, ela afirmou detestar o termo, por não ser absolutamente uma questão da arte. Para essa artista, a arte é pensamento: "o pensamento visível". E o conhecimento produzido pela pintura passa necessariamente pela experimentação - o que ela chama da relação mente-mão. "É sempre uma viagem, você não pode saber onde vai chegar. É uma aventura. Senão, você está ilustrando outra coisa que já existe."

Luis Camnitzer, artista e pedagogo uruguaio, também vê a arte como um lugar de pensamento e, para além disso, de aprendizagem. "A arte é um campo do conhecimento no qual se colocam e resolvem problemas; é o lugar onde se pode especular sobre temas e relações que não são possíveis em outras áreas do conhecimento." (CAMNITZER, 2015, s/p)

Nesse ponto podemos talvez ensaiar uma explicação inicial para as diferenças percebidas entre as produções apresentadas no Museu Berardo, da arte e da arte publicitária. A obra de arte é, para o artista imerso no processo criativo, uma viagem rumo ao desconhecido, diz Scherpenberg. E Caiafa acrescenta que tal campo criador não se esgota, uma vez pronto o trabalho do artista; ele continua potente e abrindo caminhos desconhecidos a todos que aceitem o convite da viagem. Assim, a arte incita a ver, a pensar, a imaginar. Como expressão de um pensamento em processo, ela amplia o campo do pensável; a partir de uma configuração inicial, as questões vão se multiplicando, por isso se pode afirmar ser a arte uma forma de conhecimento. Ela se coloca como inflexão, como diferença com relação ao já visto e já conhecido, implicando um risco e uma instabilidade, tanto para o autor, quanto para o interlocutor.

No caso da publicidade, o imprevisível, o intempestivo é o que se tenta controlar e reduzir desde o início; antes mesmo do processo de criação, o problema está dado, e procura-se por meio da criatividade elaborar uma resposta que exerça um efeito determinado sobre o público; a formulação de uma peça publicitária considera cuidadosamente os ingredientes a serem empregados na criação de modo ao obter um resultado previsto, positivo, mensurável e atado à solução do problema posto; nesse 
sentido não é produção de conhecimento, mas uma mescla entre transmissão de ordens, informações e ativação de afetos.

Pode-se argumentar que também a publicidade quer dar a ver e a imaginar, até a pensar; no entanto, é bem definido aquilo que deve ser visto, imaginado e pensado; permanece dentro de um circuito de reconhecimento, dentro de parâmetros e axiomas que são do âmbito do senso comum e cuja ambição é conquistar concordância. Ou seja, na publicidade a viagem é logo interrompida: remete-se alguma descoberta ao campo do conhecido e se a oferece ao interlocutor já resolvida. De fato, o mesmo pode acontecer com obras de arte, quando a potência criativa é rebatida seja sobre o preço de mercado, seja sobre uma interpretação dita correta, mas essa é uma captura localizada da qual o campo criador pode sempre escapar.

A primeira e fundamental diferença, portanto, está em se a obra propõe uma questão, convidando a subjetividade a multiplicar as variáveis em jogo, inventar possibilidades, experimentar territórios desconhecidos, ou se oferece uma solução reconfortante, reduzindo as variáveis, rebatendo a subjetividade para um território conhecido e reforçando-o. Mas isso não chega a constituir problema, afinal todo mundo precisa, em algum momento, de retornar a um abrigo confortável.

\section{Do enunciado ao agenciamento coletivo de enunciação}

Para iluminar e constituir o problema será necessário recorrer à teoria da enunciação proposta por Deleuze e Guattari em Postulados da Linguística (1995). Os autores enraízam os enunciados, vistos como a unidade elementar da linguagem, em agenciamentos coletivos de enunciação. Quer dizer: os enunciados expressam e evocam os agenciamentos coletivos; distribuem e reforçam significações baseadas numa certa ordem, própria ao agenciamento coletivo do qual se originam. Lembremo-nos que a noção de agenciamentos coletivos criada por Deleuze e Guattari delimita arranjos em que se articulam múltiplas variáveis, de conteúdo (relativo às concretudes e suas misturas) e de expressão (relativo aos regimes de signos). O modo de seleção e articulação dessas variáveis, a forma constante que elas assumem, obedecem a pressupostos implícitos e caracterizam o agenciamento. Esses pressupostos implícitos 
constituem a enunciação e envolvem variáveis discursivas e não discursivas. "Um tipo de enunciado só pode ser avaliado em função de suas implicações pragmáticas, isto é, de sua relação com pressupostos implícitos, com atos imanentes ou transformações incorpóreas que ele exprime, e que vão introduzir novos recortes entre os corpos."(DELEUZE e GUATTARI, 1995, p.23)

Avaliar os enunciados da publicidade e da arte exigiria portanto investigar suas "implicações pragmáticas", evidenciando os pressupostos implícitos que exprimem e o modo como se atribuem às concretudes. Aparece implícita nas obras e nas falas do âmbito da arte uma inquietação com o próprio tempo - a duração a que se refere Caiafa (2010); um desejo de pensamento e uma tentativa de abertura para territórios existenciais que fogem aos padrões estabelecidos - a "aventura" proposta por Scherpenberg e o "campo de pensamento" apontado por Camnitzer (2015); o experimento, a incerteza e o risco, patentes tanto nas obras de arte das vanguardas do séc. XX, quanto no modo de trabalhar dos artistas nos ateliers, são inerentes a esse desejo.

Encontramos novamente em Deleuze e Guattari a ideia de "tensores" presentes na língua, como expressões atípicas cuja potência é fazer variar, sair da norma, do padrão, e no limite, abalar as noções de norma e de padrão; isso é que chamam de desterritorializar; tornar a constante apenas uma das variações possíveis. Podemos vislumbrar nos enunciados da arte algo desses tensores, diretamente ligado a um processo incessante de invenção como virtualidade. Como um vórtice que tende a tensionar e desestabilizar as materialidades e signos que nele se encontram, o agenciamento coletivo da arte impulsiona variações e produz subjetividades heterogêneas. Nas palavras dos autores: “'Potencial' ou 'virtual' não se opõem precisamente ao real; ao contrário, é a realidade do criativo, o colocar em variação contínua das variáveis, que se opõe somente à determinação atual de suas relações constantes." (idem, p.43)

Vimos que dentre os pressupostos da publicidade estão o emprego da criatividade aplicada como solução inovadora para um problema comercial, cujo objetivo é a obtenção de um resultado em marketing, por sua vez dependente da 
produção de uma concordância em torno de um modelo estabelecido de viver. Seu compromisso fundamental com o departamento financeiro, cuja constante definidora é o retorno do investimento, torna-a avessa ao risco. Por isso, embora lance mão das variações de linguagem que brotam no âmbito da arte, como apontamos acima, o faz somente quando tais variáveis se tornaram estáveis, e de uma maneira que procura capturar a potência desejante da subjetividade para o centro constante do agenciamento coletivo do consumo. Não por acaso, os seus enunciados, mesmo quando intencional e estrategicamente questionadores, por acolher momentaneamente variações nos padrões de sexualidade, etnia, gênero, mesmo nesses casos recaem na exortação ao consumo e na apresentação do ato de consumir como força motriz da subjetividade, uma vez que o conflito se resolve pela adesão à marca. Voltamos dessa forma à constante/ postura majoritária na sociedade capitalista: reforçamos o valor do capital como meio de aquisição de todas as coisas; reforçamos o consumo privado individual como solução para problemas objetivos e subjetivos, e admitimos o mercado como perfeito mecanismo de mediação.

\section{Considerações finais}

Ao seguir a pista dos enunciados provenientes de dois setores reunidos sob a classificação de Indústria Criativa - arte e publicidade - para investigar a que se refere e qual o sentido dado aí à noção de criatividade, deparamo-nos com agenciamentos coletivos díspares. Observamos que, no âmbito da publicidade, o pressuposto implícito é a reprodução do capital por meio do emprego de pequenas novidades capazes de atrair e capturar o desejo, enquanto promove uma subjetividade capitalística homogeneizante. No âmbito da arte, o pressuposto é outro: produzir pensamento por meio da colocação de problemas disruptivos, que podem impulsionar variações de subjetividade e desejo cujo desfecho é imprevisível.

Percebemos nos pressupostos implícitos da publicidade a coerência com o projeto da Indústria Criativa - a criatividade compreendida como insumo na produção de valor econômico a partir do simbólico -, o que indica ser a publicidade parte desse agenciamento. Já os pressupostos implícitos da arte - pensamento, invenção, ruptura como se enquadrariam nessa racionalidade? Qual seria a aceitabilidade do risco e a 
abertura para o imprevisível, para a dificuldade e até mesmo para o incompreensível, quando o pressuposto é o sucesso econômico, cuja medida é dada pelo mercado?

Se pensarmos em termos de agenciamentos coletivos, inferimos que o simbólico nunca é destacado das concretudes, eles se pressupõe, e a forma de sua articulação determina certas escolhas, certos encadeamentos, além de por em andamento subjetividades. O próprio enunciado "Indústria Criativa" se revela, não uma contradição, como inicialmente vislumbramos, mas uma das palavras de ordem do agenciamento capitalístico, ou seja, uma estratégia. Mais do que referir-se a uma realidade preexistente, o termo recorta e alinha fenômenos distantes, constituindo aquilo mesmo que aponta, na tentativa de ordenar e se apropriar, segundo o modelo de desenvolvimento capitalista, da potência perturbadora da invenção, acorrentando-a ao seu pressuposto imperativo de expansão do lucro.

\section{Referências}

AGAMBEN, Giorgio. O que é o contemporâneo? e outros ensaios. Chapecó, SC: Argos, 2009. AUTOR. "Compre essa ideia, consuma esse produto", ou como a publicidade nos enreda em sua teia. In: Revista FAMECOS: mídia, cultura e tecnologia, v.21, n.3, 2014.

CAIAFA, Janice. Nosso século XXI: Notas sobre arte, técnica e poderes. Rio de Janeiro: Relume-Dumará, 2000.

CAMNITZER, Luis. O artista, o cientista e o mágico. In: Ilusões. Rio de Janeiro: Casa Daros, 2015

DELEUZE, Gilles e GUATTARI, Felix. Mil Platôs: Capitalismo e esquizofrenia, vol.2. Rio de Janeiro: Ed. 34, 1995.

ECO, Umberto. A definição da arte. Lisboa: Edições 70, 2011 (1981)

KASTRUP, Virginia. A invenção de si e do mundo: Uma introdução do tempo e do coletivo nos estudos da cognição. Belo Horizonte: Autêntica, 2007. [1a edição: Papirus, 1999]

MINISTÉRIO DA CULTURA. Plano da Secretaria da Economia Criativa: políticas, diretrizes e ações, 2011 - 2014. Brasília, 2011.

MORAIS, Frederico. 801 definições sobre arte e o sistema da arte. Rio de Janeiro: Record, 2002

OSTROWER, Fayga. Criatividade e processos de criação. Petrópolis: Vozes, 1987.

SANTOS, Rui Afonso. O Consumo feliz. Lisboa: Museu Coleção Berardo, 2014 (disponível em $<$ http://pt.museuberardo.pt/exposicoes/o-consumo-feliz> acesso em 03 de maio de 2018) UNCTAD United Nations Conference on Trade and Development. Creative Economy Report, 20 